\title{
Experiência Integradora: avanços progressivos no olhar discente acerca do trabalho interdisciplinar
}

\author{
Experiencia Integradora: avances progresivos en la mirada estudiante \\ acerca del trabajo interdisciplinar
}

\author{
Integrating Experience: progressive advances in the look at the student of \\ interdisciplinary work
}

\author{
Jucenir Garcia da Rocha ${ }^{1}$
}

\begin{abstract}
Resumo
O texto reporta-se aos olhares discentes de turmas de terceiro ano do Ensino Médio acerca do movimento (inter)disciplinar ensejado em aulas conjuntas em componentes de Ciências Humanas. Para tanto o trabalho mira entender a dinâmica de concretude da integração no ensino e principalmente da interdisciplinaridade em contraste análogo à visão preponderante que evoca às tarefas como fruto de meras missões metodológicas, fundadas na vontade dos profissionais. Além disso, busca-se definir à luz do pensamento de Moraes, (1997); Gramsci, (2005) caracterizações elementares à esta dinâmica; de modo a dirimir os efeitos da dispersão polissêmica. Assim, sob o crivo da concretude as atividades de ensino-aprendizagem são avaliadas pelos participantes, com ênfase nos relatos dos estudantes que perpassam pelas narrativas que aludem à ideia inicial de justaposição, avançando para noção de visão geral; do "todo junto" e abrindo posteriormente para a dimensão do trabalho que permite o surgimento de ângulos diversos na aparição dos conceitos, interligando posteriormente suas conexões que se densificam no campo da contextualização das aulas. Por fim, esta sistematização das vozes permite captar a capacidade de fazer relações entre as classes, atingindo seu apogeu no momento propriamente interdisciplinar como fruto de uma oportunidade histórica de trabalho escolar bem sucedido.
\end{abstract}

Palavras-Chave: Interdisciplinaridade; visão de estudantes; Ensino integrado; Ciências Humanas; Ensino Médio

\section{Resumen}

El texto se refiere a las miradas discentes de clases de tercer año de la Enseñanza Media acerca del movimiento (inter) disciplinar que se enseña en clases conjuntas en componentes de Ciencias Humanas. Para tanto el trabajo mira entender la dinámica de concreción de la integración en la enseñanza y principalmente de la interdisciplinaridad en contraste análogo a la visión preponderante que evoca a las tareas como fruto de meras misiones metodológicas fundadas en la voluntad de los profesionales. Además, se busca definir a la luz del pensamiento de Moraes, (1997); Gramsci, (2005) caracterizaciones elementales a esta dinámica; de modo que dirija los efectos de la dispersión polisémica. Así, bajo el cribado de la concreción las actividades de enseñanzaaprendizaje son evaluadas por los participantes, con énfasis en los relatos de los estudiantes que pasan por las narrativas que aluden a la idea inicial de la yuxtaposición, avanzando hacia la noción de visión general; de "todo junto" y abriendo posteriormente hacia la dimensión del trabajo que permite el surgimiento de ángulos diversos en la aparición de los conceptos, interconectando posteriormente sus conexiones que se densifican en el campo de la contextualización de las clases. Por último, esta sistematización de las voces permite captar la capacidad de hacer relaciones entre las clases, alcanzando su apogeo en el momento propiamente interdisciplinario como fruto de una oportunidad histórica de trabajo escolar exitoso.

Palabras claves: interdisciplinariedad; visión de los estudiantes; Enseñanza integrada; Ciencias Humanas; Enseñanza Media

\footnotetext{
${ }^{1}$ Professor de Filosofia - Magistério Estadual do RS; Técnico em Assuntos Educacionais lotado no Núcleo de Desenvolvimento Educacional da Universidade Federal do Pampa; Jaguarão, RS, Brasil; jussors@ gmail.com
} 


\begin{abstract}
The text refers to the student looks of third-year high school classes about the (inter) disciplinary movement in joint classes in components of Human Sciences. For this, the work aims to understand the dynamics of concreteness of integration in teaching and especially interdisciplinarity in contrast analogous to the preponderant view that evokes tasks as a result of mere methodological missions, based on the will of professionals. In addition, it is sought to define in the light of the thought of Moraes, (1997); Gramsci, (2005) elementary characterizations to this dynamic; in order to resolve the effects of the polysemic dispersion. Thus, under the sieve of concreteness the teaching-learning activities are evaluated by the participants, with emphasis on the students' reports that go through the narratives that allude to the initial idea of juxtaposition, advancing towards the notion of general vision; of the "all together" and later opening to the dimension of the work that allows the emergence of diverse angles in the appearance of the concepts, later connecting their connections that are densified in the field of contextualization of classes. Finally, this systematization of voices allows capturing the capacity to make relations between classes, reaching its apogee at the proper interdisciplinary moment as the result of a successful historical opportunity for successful schoolwork.
\end{abstract}

Keywords:. Interdisciplinarity; students' vision; Integrated teaching; Human Sciences; High school

\title{
1.Introdução
}

O presente trabalho reporta-se a excertos de temática central em uma pesquisa realizada no âmbito da Pós-Graduação stricto sensu em nível de Mestrado em Educação da Universidade Federal do Pampa, realizada durante o período de dois mil e quinze (2015) à dois mil de dezessete (2017). O lócus desta pesquisa foi o Colégio Estadual - Carlos Alberto Ribas / CECAR; com foco de trabalho com duas turmas de terceiro ano do Ensino Médio Politécnico, na cidade de Jaguarão, Estado do Rio Grande do Sul.

Com eixo central na integração curricular, supostamente anunciada em documentos e demais instrumentos de formação da Secretaria de Educação do Governo do Estado do Rio Grande do Sul na ocasião este texto traz a baila uma série de impressões dos discentes em voga, expressas em instrumento com questões abertas e outras fechadas, acerca da experiência em três encontros de quatro (4) horas em ensino desenvolvido de forma integrada entre dois professores, abrangendo a totalidade da área de Ciências Humanas constituída pelos componentes curriculares de História, Geografia, Filosofia e Sociologia. Para tal, por opção metodológica a pesquisa não distingue as falas individualmente, mas apenas pela posição dos sujeitos na estrutura institucional, de modo que os mesmos serão aqui identificados pela sigla E3º AEMP para designar Estudantes de Terceiro Ano do Ensino Médio Politécnico ao passo que a sigla E.E. refere-se a denominação para Educador Engajado para designar o profissional que atuou em conjunto nesta atividade.

Todavia, com afeite de superar a mera expressividade do aluno empírico (SAVIANI, 1989), os escritos discentes constam devidamente sistematizados em prol de uma análise mais acurada aos domínios dos limites e possibilidades que ensejaram as visões progressivas neste 
trabalho. A questão chave que se evoca como o problema de grande monta a ser desmistificada neste artigo reside nas miradas voluntaristas que ostentam uma integração interdisciplinar nos marcos de um apelo a vontade dos educadores, não raras vezes desenraizadas do contexto ou da necessidade concreta para tamanho emolumento. Não obstante, a proposta da Secretaria de Educação do Estado do Rio Grande do Sul (SEDUC-RS) (RIO GRANDE DO SUL, 2011, 2012) referenciava com indicativos de integração interdisciplinar nesta direção, ainda que, paradoxalmente, contrastante com a referência usada pela mesma para situar a politecnia. Além do mais, vale grifar o papel da dispersão polissêmica acerca da interdisciplinaridade como elemento exponencial da profusão conceitual como um elemento complicador de estratégias ao ensino integrado.

Em face ao descrito, as exposições aqui expostas miram entender a dinâmica de concretude da integração no ensino e principalmente da interdisciplinaridade em contraste análogo à visão preponderante que evoca às tarefas como fruto de meras missões metodológicas, fundadas na vontade dos profissionais. Além disso, busca-se definir à luz do pensamento de Moraes, (1997); Gramsci, (2005) caracterizações elementares à esta dinâmica; de modo a dirimir os efeitos da dispersão polissêmica.

Para tal, sob o crivo da concretude as atividades de ensino-aprendizagem são avaliadas pelos participantes, com ênfase nos relatos dos estudantes que perpassam pelas narrativas que aludem a ideia inicial de justaposição, avançando para noção de visão geral; do "todo junto" e abrindo posteriormente para a dimensão do trabalho que permite o surgimento de ângulos diversos na aparição dos conceitos, interligando posteriormente suas conexões que se densificam no campo da contextualização das aulas. Por fim, esta sistematização das vozes permite captar a capacidade de fazer relações entre as classes, atingindo seu apogeu no momento propriamente interdisciplinar como fruto de uma oportunidade histórica de trabalho escolar bem sucedido.

\section{Integração Curricular: avanços progressivos na compreensão da concepção}

Por tratar-se do tema central entendeu-se que o tópico merecesse uma relatoria pormenorizada sobre a captação dos sentidos do conceito no dinamismo da prática empreendida, razão pela qual anuncia-se este passo a passo categorial nas expressões dos educandos. 


\subsection{Justaposição}

A primeira remete ao sentido daquilo que preponderou na experiência do primeiro encontro das aulas desenvolvidas conjuntamente na área: a multidisciplinaridade. Veja-se nas falas:

\footnotetext{
Acredito que isoladas a gente consegue aprender com mais facilidade, porém com elas juntas, tem uma interação maior (E3 ${ }^{\circ} \mathrm{AEMP}$, grifo do redator);

Foi uma boa aula por juntar todas as perspectivas da área de Ciências Humanas em geral (E3 ${ }^{\circ} \mathrm{AEMP}$, grifo do redator).
}

Desta forma, convém denotar destas duas falas que a palavra "juntas" e o verbo "juntar" remetem igualmente a uma conotação de justaposta à integração curricular, características constatadas suficientente em relevo nas ações do primeiro encontro integrado.

Vale registrar que nas primeiras ações integradas as aulas praticamente não foram capazes de transcender os limites da multidisciplinaridade, embora jamais se tivesse abandonado o caminho da síntese, em que pese à abalizada concepção de Moraes (1997, p. 182) ao considerar que "[...] pluri ou multidisciplinaridade é a justaposição de várias disciplinas sem nenhuma tentativa de síntese". Vale reconhecer que esta questão disciplinar comporta várias interpretações e esta experiência não abrange a pluridisciplinaridade pelo fato dessa integração não evadir o âmbito de uma única área do conhecimento, no caso as Ciências Humanas. Todavia, mirou-se o estudo com intuito de não dispersar o entendimento na polissemia produzida pela "liquidez pós-moderna".

\footnotetext{
Muito se houve falar em multidisciplinaridade, interdisciplinaridade e transdisciplinaridade, no entanto, se buscarmos uma compreensão mais aprofundada desde novo discurso perceber-se-á que a ideia mais discutida e praticada, em geral, é a multidisciplinaridade (PETRAGLIA, 1993 apud PIRES, 1998, p. 175).
}

Neste sentido, é mister que se reconheça em tom de concretude que o amálgama produzido nesta fase da experiência pouco se ungiu da pretensa interdisciplinaridade, uma vez que estas intervenções ainda preservaram elementos um tanto parciais de cada componente, talvez pela apreensão da experiência nova em primeiro encontro a despeito de qualquer narrativa acrobática impulsionada pelo método de execução apriorístico herdado do programa institucional stricto sensu. (UNIVERSIDADE FEDERAL DO PAMPA, 2011). Contudo, em contraposição a afirmação de Moraes (1997) supramencionada, a contensão pelos componentes disciplinares não se estabeleceu por uma escassez volitiva, mas por limitações mesmo num universo de quem - ao mais das vezes -, não foi educado a vivenciar esta prática. 
Todavia, no campo doutrinário, Gramsci adverte com uma postura muito socrática, que parece adivinhar que sua projeção para a Escola Unitária viria a ser confundida posteriormente como neste caso da politecnia:

[...] deve-se ser justo com os adversários, no sentido de que é necessário esforçar-se para compreender o que eles realmente quiseram dizer, e não fixar-se maliciosamente nos significados superficiais e imediatos de suas expressões (GRAMSCI, 2004, p. 123).

Destarte, será revisitada a expressão da autora em subseção posterior, em um contexto mais ampliado, onde parece indicar que nesta frase vista isoladamente o seu sentido não tenha sido tão preciso. Por ora, sofrear-se- a interpretar os reflexos desta ação por um sentido mais singelo; o de que

[...] a multi, ou a pluridisciplinaridade implicam quando muito, o aspecto integração de conhecimentos, poder-se-ia dizer que a integração ou a pluri ou a multidisciplinaridade seria uma etapa da integração para interdisciplinaridade [...] (FAZENDA,1992, p. 40).

Ademais, vale grifar que, pelo menos neste caso, a integração curricular e mesmo a interdisciplinaridade não tem o propósito de tratar os componentes curriculares específicos como se fosse uma anomalia. Ao contrário, há também que se reconhecer as contribuições disciplinares no universo das produções históricas do conhecimento. Em uma obra que enuncia a superação da interdisciplinaridade como uma "filosofia do sujeito" os autores explicam que

Não procederiam, por isso, as análises que captam a disciplinaridade como uma patologia e/ou cancerização. Vemos na disciplinaridade o "não objeto" da interdisciplinaridade, isto é, é impensável a interdisciplinaridade sem a base que a possibilita, ou seja, as disciplinas (JANTSCH; BIANCHETTI, 2011, p. 31).

Em suma, cabe concluir que os passos para a integração teriam que partir de alguma base existente, que em neste caso eram justamente as disposições curriculares específicas institucionalizadas no projeto seguido pela Escola para orientar o diálogo com esta escolha.

\subsection{Visão geral}

Numa segunda classificação avista-se expressões que avançam no sentido da visão holística sob o objeto de estudo e não deixa de comungar com alguns elementos circunscritos 
na carta do cárcere de 03 de abril de $1933^{2}$,no que diz respeito à totalidade, o preparo geral e harmonioso que pareceu suscitado neste tipo de integração. Vejamos:

- Os temas eram trabalhados mais no geral e não tão detalhadamente devido ao tempo, porém isso não prejudicou a qualidade em nenhum momento (E3 ${ }^{\circ} \mathrm{AEMP}$, grifo do redator);

- A vantagem foi perceber como filosofia pode ser ligado a geografia, fato que antes eu não tinha ideia. Acabamos tendo uma visão mais geral dos temas e isso foi muito legal (E3 ${ }^{\circ} \mathrm{AEMP}$, grifo do redator);

- As aulas tiveram bastante pontos positivos, dos quais eu destacaria seria que o conteúdo foi bastante abrangente [...] (E3 ${ }^{\circ}$ AEMP, grifo do redator).

Vale observar por intermédio dos grifos os traços comuns de exclamação neste sentido do todo.

\subsection{Todo junto}

Contudo, ao alocar excertos da avaliação do professor dizendo que “[...] as aulas integradas entre as disciplinas, mas ministradas individualmente são positivas por permitir a visão do todo" [...] (E.E., grifo do redator) percebe-se que a mesma ainda pareceu constrita ao papel promotor da totalidade. Todavia, ao analisar a preparação para as aulas integradas na moldura que proposta, o professor menciona que "[...] uma dificuldade 'natural' foi adaptar os objetivos e conteúdos das disciplinas, de modo a propiciar um foco comum, sem prejuízo da diversidade de visões" (E.E., grifo do redator). Não obstante, é reverberado em outra fala de aluno uma elevação de sentido à prática em mesma direção na afirmação que "[...] as aulas integradas foram muito satisfatórias, pois nelas apendi que todas as matérias estão sempre em conjunto $[\ldots]$ ". (E3 ${ }^{\circ} \mathrm{AEMP}$, grifo do redator).

Disto decorreu uma síntese que fundiu aquela visão geral do "todo" no "juntos" e vice-versa; de modo que nesta disposição só cabe a denominação do "todos juntos".

\section{4 Ângulos diversos}

A propósito das "visões do todo" em "foco comum", vale dizer que o "não prejuízo das diversidades" parecia entoar, mesmo que subliminarmente certo cuidado em não tornar

\footnotetext{
${ }^{2}$ Não pense que eu tenha perdido, sequer por um momento, nenhuma pontinha de minha serenidade, como você diz. No máximo, quando me sinto fisicamente fraco, perco a vontade de me ocupar com qualquer coisa que seja alheia a minha preciosa pessoa física; acontece como quando se deve fazer um grande esforço para levantar determinado peso, trincam-se os dentes e não se fala nada, para que se possa concentrar inteiramente no esforço imediato. Todos, [...] já se viram ou vão se ver em situações semelhantes. Parece-me que deve explicar este conceito a Mea, para que não perca a coragem e continue a estudar de todos os modos; numa hipótese infeliz, ela pode perder alguns anos como tempo material numa determinada sequência escolar, mas não os perderá inteiramente se melhorar a cada dia sua cultura, seu preparo geral, se ampliar o horizonte de seus conhecimentos e de seus interesses intelectuais (GRAMSCI, 2005, p. 323-324 - Grifo do redator).
} 
estes atos integrados em um insight totalitário, razão de preservar os ângulos diversos. É o que grafa a dita que "[...] as aulas integradas são bem interessantes uma vez que ambas as matérias podem ser vistas de ângulos diferentes, podemos por exemplo analisar a política de forma filosófica” (E3 AEMP, grifo do redator).

Tais contornos lembram os momentos em que, inclusive houve divergência em algum ponto específico pelos regentes de classe em praticamente todos os encontros. Ademais, a própria entonação característica de cada professor em referência ao observado em outros momentos por tematizações mais afastadas da centralidade deste debate por si só já implicaria de certa maneira alguma visão um tanto diversa acerca do objeto analisado.

\subsection{Esboça um sentido de conexão}

Ainda que apresentada de maneira um pouco mecânica convém trazer a tona uma exposição mirando naquilo que exprime de conexão entre as matérias estudadas. A ver: "Achei algo diferente e inovador que pode nos ajudar e facilitar nossa compreensão com a função das aulas, podendo nos fazer perceber que todas estão interligadas" (E3º AEMP, grifo do redator).

\subsection{Porém, validado pela contextualização}

Contudo, de outra fala é possível extrair pela interpretação do sentido ao qual confere sua confusão mental aos assuntos, um caráter de contextualização à experiência. Liga-se a ela: "Acabei me confundindo um pouco sobre os assuntos tratados, porem consegui aprender bastante e achei produtivas e contextualizadas” (E3 ${ }^{\circ} \mathrm{AEMP}$, grifo do redator).

De modo a aferir importância a tais conexões, vale reportar-se à carta do cárcere de 14 de dezembro 1931 endereçada à Lulca, sob a qual Gramsci manifesta suas desconfianças mais fugazes em relação aos rumos da educação soviética no que concerne a formação integral dos sujeitos cognoscentes. Nela dizia:

[...] tenho muito interesse em saber como foi inserido na escola primária o princípio das brigadas de assalto ${ }^{3}$ e os nichos especializados, e qual objetivo pedagógico se propõe alcançar. Pode nascer a dúvida de que isto acelere artificialmente a orientação profissional e distorça as inclinações das crianças, fazendo perder de vista o objetivo da escola única de conduzir as crianças a um desenvolvimento

\footnotetext{
3 'Parece-me que, por 'brigadas de assalto', se deva entender o 'método de laboratório por pelotões', variante soviética ('a tradução em russo', tem-se vontade de dizer) do Plano Dalton concebido por Helen Parkhurst; uma variante que consistia em aceitar o princípio do planejamento do trabalho autônomo dos alunos, afastando-se, porém os riscos do individualismo pela acentuação do trabalho em grupo" (MANACORDA, 2008, p.107). Os nichos especializados referiam-se à viveiros reservados para animais domésticos.
} 
harmonioso de todas as atividades, até que a personalidade formada acentue as inclinações mais profundas e permanentes, porque nascidas no nível mais alto de desenvolvimento de todas as forças vitais, etc., etc. (GRAMSCI, 2005, p. 134, grifo do redator).

Visto desta forma, parece evidente que a integração sob a qual se refere busca conexões harmoniosamente o suficiente enquanto alternativa unitária à dualidade estrutural no ensino que de alguma maneira a proposta politécnica da SEDUC RS, ao seu jeito, tentou instaurar. O fato do autor em voga se reportar em referência à escola primária não esteriliza sua pertinência para este estudo, sobretudo porque “[...] a 'escola única', instituída em 1923 na União Soviética” (GRAMSCI, 2005, p. 135), a qual se reporta, “[...] aboliu a distinção entre o grau primário e os subsequentes e procurou eliminar as diferenças entre a educação profissional, técnica, científica e humanista" (GRAMSCI, 2005, p. 135).

\subsection{Capacidade de fazer relações}

Tais conectividades erguem-se de forma mais substantivas em expressões traduzidas pela capacidade de fazer relações, a exemplo desta avaliando que " [...] as aulas integradas foram boas, por juntar disciplinas que de um jeito ou de outro já estavam conectadas” (E3 ${ }^{\circ} \mathrm{AEMP}$, grifo do redator).

O vigor desta fala interpõe ao artificialismo da gradeação curricular e evidencia o seu anacronismo, ao tempo que o modelo de grade subentende que os estudantes farão sozinhos estas relações; o que nem sempre ocorre, talvez porque a tarefa individual se torne um tanto hercúlea aos discentes, que, por sua vez, disseram que nas aulas integradas "[...] é possível compreender de forma melhor as relações entre os assuntos tratados em cada disciplina das ciências humanas" (E3AEMP, grifo do redator). Como se não bastasse, corroboraram para encorpar este acinte outras relações em profundidade de maior alcance conforme descrição subsequente:

\footnotetext{
- As aulas integradas me ajudaram muito e relacionar os temas de humanas não só com matérias do terceiro ano mas ao longo da minha trajetória (E3 $\left.{ }^{\circ} \mathrm{AEMP}\right)$;

- Em geral foram boas, pois foi possível compreender relações entre matérias, pessoas e acontecimentos dentro das disciplinas de Ciências Humanas (E3 ${ }^{\circ}$ AEMP, grifo do redator).
}

\subsection{Momentos interdisciplinares}

Estas incursões outorgam repor ao debate uma dimensão propalada no relato de excertos do primeiro encontro dispostas na item 2.1. Em impulso metacognitivo, vale lembrar 
que chegou-se a anunciar que era prudente e justo extrair de forma mais abrangente o conceito sobre o multi e pluridisciplinar, esboçado naquela ocasião recortadamente do discurso de Moraes (1997). Vale lembrar que neste segundo encontro durante dialogo em círculo na quadra de esportes chegou um momento em que o relator que subscreve este texto sentiu a certeza de estar vivenciando inequivocamente um momento interdisciplinar. Antes disso, vale delimitar o contexto em que Moraes (1997, p. 182) define que

Pluri ou multidisciplinaridade é a justaposição de várias disciplinas sem nenhuma tentativa de síntese. A interdisciplinaridade, segundo Pierre Weil (1993), trata da síntese de duas ou mais disciplinas, transformando-as num novo discurso, numa nova linguagem e em novas relações estruturais. A transdisciplinaridade seria o reconhecimento da interdependência entre vários aspectos da realidade. É a consequência normal da síntese dialética provocada pela interdisciplinaridade bemsucedida.

Daquele momento anunciado, recorda-se que no alto das discussões o professor com o qual contava para o trabalho, voltou-se para o grupo e disse: "agora eu falei de Filosofia e ele falou de Sociologia!" Quer dizer, era comum àquele correr das discussões que não mais se fizesse qualquer delimitação do que fosse território de uma ou de outra performance disciplinar, de tal sorte que todos sentiam-se a vontade de falar de tudo e sobre tudo aquilo que se reportasse ao objeto estudado. Todavia, o mais importante de tudo é que este momento evocado serviu para que ambos percebessem de que já haviam produzido sínteses em novas linguagens e relações sem mesmo saber ou dar-se de conta naquele momento da prática educativa.

Embora irrelevante para alteração do sentido da análise, este contexto intercorre pensar que "nenhuma tentativa de síntese" de Moraes (1997) seja mais uma "figura de expressão" para evidenciar a necessidade de efetiva produção de síntese ao momento interdisciplinar. Finalmente encerra-se esta seção com a convicção de que não basta tão somente agrupar componentes e profissionais para produzir esta síntese cultural, tão pouco que se possa prescindir de momentos similares a estes para consecução do "homem novo" ou se preferir-se; do "novo tipo de intelectual" (GRAMSCI, 2001, p. 53).

\section{Referências}

FAZENDA, Ivani. Integração e interdisciplinaridade no ensino brasileiro: efetividade ou ideologia. São Paulo: Loyola, 1992. 
GRAMSCI, Antônio. Cadernos do cárcere. Tradução de Carlos Nelson Coutinho. 2. ed. Rio de Janeiro: Civilização Brasileira, 2001, 2 v.

Cadernos do cárcere. Tradução de Carlos Nelson Coutinho. 3. ed. Rio de Janeiro: Civilização Brasileira, 2004, 1 v.

Cartas do cárcere. Tradução de Luiz Sérgio Henriques. Rio de Janeiro: Civilização Brasileira, 2005, $2 \mathrm{v}$.

JANTSCH, Ari; BIANCHETTI, Lucídio. Interdisciplinaridade: para além da filosofia do sujeito. In: JANTSCH, Ari; BIANCHETTI, Lucídio (Orgs.). Interdisciplinaridade: para além da filosofia do sujeito. 9. ed. Petrópolis: Vozes, 2011, p. 19-33.

MORAES, Maria Cândida. O paradigma educacional emergente. 5. ed. Campinas: Papirus, 1997.

PIRES, Marília Freitas de Campos. Multidisciplinaridade, interdisciplinaridade e transdisciplinaridade no ensino. Interface - Comunicação, Saúde, Educação, São Paulo, v. 2, n. 2, p. 173-182, 1998. Disponível em: 〈http://hdl.handle.net/11449/30363>. Acesso em: 20 jul. 2017.

RIO GRANDE DO SUL. Proposta Pedagógica para o Ensino Médio Politécnico e educação profissional integrada ao ensino médio - 2011-2014. Porto Alegre: Secretaria Estadual de Educação do Rio Grande do Sul, 2011.

Parecer $n^{\circ}$ 310/2012. Aprova o Regimento Escolar Padrão para o ensino médio "politécnico" a ser adotado por escolas da Rede Pública Estadual que solicitarem credenciamento e autorização para o fundamento desse curso a partir do ano letivo de 2012. Conselho Estadual de Educação. Aprovado em 04 de abril de 2012. Disponível em: $<$ http://servicos.educacao.rs.gov.br/dados/ens_med_regim_padrao_em_Politec_I.pd >. Acesso em: 02 fev. 2018.

SAVIANI, Demerval. Sobre a concepção de politecnia. Rio de Janeiro: Fundação Oswaldo Cruz, 1989.

UNIVERSIDADE FEDERAL DO PAMPA. Regimento do Programa de Pós-Graduação em Educação Stricto Sensu em Educação - Mestrado Profissional. Jaguarão: UNIPAMPA, 2011. Disponível em: <http://cursos.unipampa.edu.br/cursos/ppgedu/files/2015/12/Regimento-doPPGEdu.pdf $>$. Acesso em: 20 jul. 2017 